cases collected by Sir William Gowers up to 1888 , all of which were fatal.

Nevertheless, the mortality for multiple brain abscesses in almost everyone's hands is $100 \%$. Ramamurthi and Narasimhan (1957) had two multiples in 62 patientsboth died ; Sperl, MacCarty, and Wellman (1959) lost all three multiples out of 60 cases, though Loeser and Scheinberg (1957) saved two out of eight appearing in a series of 88 cases. In this series all 10 patients died. While we must therefore welcome the undoubted reduction in disease incidence, morbidity, and mortality produced by early antibiosis and adequate treatment of predisposing lesions, the experience of this series would appear to be threefold: firstly, that the overall incidence of brain abscess will be reduced in frequency in those parts of the world where the standard of living is high ; secondly, the commonly occurring solitary abscesses will be replaced by the multiple kind, which are virtually untreatable by surgical means; and, thirdly, that by the time almost any abscess comes under observation pus is present and demands release. Therapy directed towards decompression and temporization would not seem to be indicated, though this is partially explained by the fact that in the solitary group many patients did not come to hospital until the symptoms were very serious, while in the multiple group a very invasive organism was undoubtedly present. Ramamurthi and Narasimhan (1957) stress the importance of the preliminary inflammatory phase in their series of 48 patients, who must resemble many of the patients studied here, yet their conclusion is not supported by this evidence.

In this series of 29 brain abscesses, 10 (34\%) were multiple, and all 10 patients died. If this is the shape of things to come it would seem that the wheel of mortality may turn a full circle back to Sir William Gowers and his $100 \%$ death rate for the condition. If it does so we can only take consolation in the fact that those cases which would previously have been amenable to surgery have been removed by the antibiotic filter and have never proceeded as far as brain abscess formation.

\section{Summary}

A series of 29 cases of brain abscess occurring in a mixed European and African population is reported. The cases are divided into two groups, solitary abscesses (19 cases) and multiple abscesses (10 cases). The solitary group consists almost entirely of Africans and the multiple group of Europeans. The mortality in the solitary group is $36 \%$, in the multiple group $100 \%$. It is my contention that Africans predominated in the solitary group because of their poorer standard of living and health and late attendance for medical treatment, so that any infection severe enough to produce a multiple abscess kills the patient before such a complication sets in. On the other hand, Europeans have a high standard of living and attend early for medical treatment. Mild infections sufficient to produce a solitary abscess are controlled before any complications can occur. Those infections, previously severe enough to kill the patient at an early stage of the illness, produce multiple abscesses because the patient now survives long enough to develop these complications. Thus with increasing standards of living, although the overall incidence of brain abscess will be reduced, the abscesses that will be seen by clinicians will become more severe.

I am indebted to Mr. Peter Clifford, of Nairobi, for permission to report Case 8, to Professor T. I. Hoen, of New York, for Case 15, to Professor N. Dott, of Edinburgh, for Case 23, and to Dr. Stanley Stellar, of New York, for Case 24.

\section{REFERENCES}

Botterell, E. H., and Drake, C. G. (1952). J. Neurosurg., 9, 348. Loeser, E., and Scheinberg, L. (1957). Neurology, 7, 601.

Pennybacker, J. (1950). Ann. roy. Coll. Surg. Engl., 7, 105.

Ramamurthi, B., and Narasimhan, S. T. (1957). J. int. Coll. Surg., 28, 589.

Sperl, M. P., MacCarty, C. S., and Wellman, W. E. (1959). Arch. Neurol." (Chic.), 81, 439 .

\title{
RENAL ARTERIOVENOUS FISTULA AFTER PERCUTANEOUS RENAL BIOPSY
}

BY

S. BLAKE, M.D., M.Sc., M.R.C.P., M.R.C.P.Ed.

S. HEFFERNAN, M.Ch., F.R.C.S.I.

P. McCANN, M.D., M.Rad., F.F.R., D.M.R.D.

Cardiac Department, Mater Misericordiae Hospital, Dublin

Arteriovenous fistula of the renal vessels is a rare condition. A total of 32 cases have been reported in the literature (Twigg, Pradhan, and Perloff, 1962; Boijsen and Kohler, 1962). Of these, 13 were thought to be congenital, three were due to renal carcinoma, and five were of traumatic origin. The remainder followed surgical procedures, usually nephrectomy, with development of fistula in the vascular pedicle. However, arteriovenous fistula can also occur after percutaneous needle biopsy, and the purpose of this communication is to draw attention to the possibility of this complication of a relatively common investigation and to report two cases.

\section{Case 1}

A girl aged 19 presented with headache and was found to have a blood-pressure of $170 / 110$. There was no cardiac enlargenent or gallop rhythm. The fundi were normal. No evidence of coarctation was found. A faint systolic bruit was audible in the epigastrium to the right of the midline.

There was no proteinuria; the blood urea was normal Urine culture was negative, but the white-cell excretion rate was grossly elevated. The 24 -hour catechol excretion was in the normal range. Serum potassium was normal. An intravenous pyelogram showed nothing abnormal. Divided renal studies showed a significant increase in creatinine excretion and a diminution in sodium on the right side. Renal angiography showed no definite abnormality, but the proximal part of the right renal artery was overlapping the spine, and was not adequately visualized. Left renal biopsy produced an adequate specimen of cortex together with $a$ tiny portion of medulla. Histological examination showed no abnormality. The patient was discharged on hypotensive therapy. Six months later reinvestigation confirmed the previous results of divided renal studies and white-cell excretion rate. Renal angiography showed a moderate stenosis of the proximal right renal artery. In addition, however, there was a large arteriovenous fistula in the mid-zone of the 
left kidney, with immediate filling of dilated renal veins and visualization of dye in the vena cava (Figs. 1 and 2). Auscultation disclosed a loud continuous murmur at the left renal angle that was not present at the original examination.

The patient was again discharged on hypotensive therapy with a B.P. of $130 / 90$. When last examined, about nine months later, she had stopped her treatment and the B.P. had returned to its original level of $170 / 110$. Her heart had not increased in size from the original examination.

\section{Case 2}

A man aged 41 presented with visual symptoms, and examination revealed hypertension in the malignant phase. B.P. was $240 / 150$. There was clinical, radiological, and electrocardiographic evidence of left-ventricular enlargement, and a presystolic gallop rhythm was present at the apex. There were no renal bruits or evidence of coarctation. Urine examination showed a trace of protein with a moderate number of red cells. Urine culture was negative and the white-cell excretion rate was normal both before and after intravenous hydrocortisone. Blood urea was 37 $\mathrm{mg} . / 100 \mathrm{ml}$. Serum potassium was normal. The 24-hour catechol excretion was in the normal range. Intravenous pyelography showed poor excretion of dye, but no structural abnormality of the kidneys was seen.

Renal biopsy of an adequate sample of cortex showed evidence of nephrosclerosis. Renal angiography, performed three weeks after renal biopsy, revealed a small arteriovenous fistula in the mid-zone of the left kidney. Premature

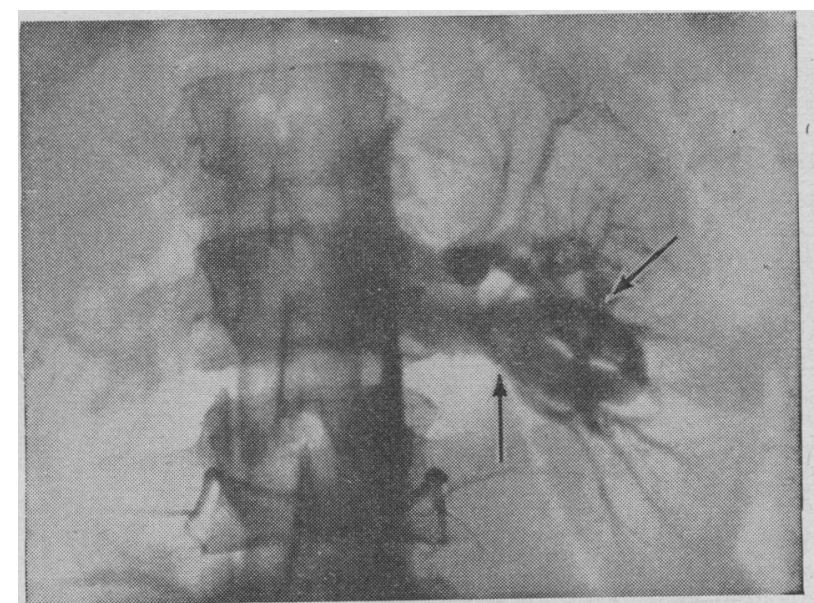

Fio, 1- Case 1. Kepeat arteriogram sux munths atter left renal biopsy, showing large left A.V. fistula (upper arrow), with immediate filling of dilated veins. Lower arrow indicates a large renal vein.

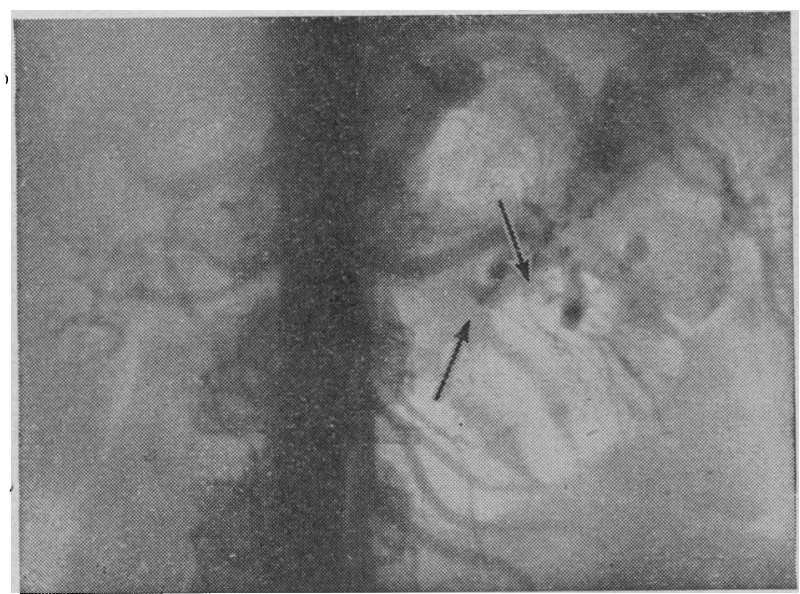

Fig. 3.- Lase 2. Kellal anglogram tnree weeks arter left renal biopsy. Upper arrow indicates a small arteriovenous fistula on left side with early venous filling (lower arrow). filling of renal veins had occurred, but no dye could be seen in the vena cava (Figs. 3 and 4). After this discovery an examination for bruits revealed a loud continuous murmur at the left renal angle.

The patient was treated with hypotensive agents, and at the last examination his B.P. was $150 / 90$. The heart had not changed in size since the original examination.

\section{Discussion}

The value of renal biopsy in the investigation of renal disease is well established. However, against this must be weighed the complications of the procedure. These include haemorrhage, infection, and puncture of adjacent organs, which have been fully discussed elsewhere (Kerr, 1961). To them, however, must now be added renal arteriovenous fistula. Boijsen and Kohler (1962) reported five cases of renal arteriovenous fistula, two of which they ascribed to percutaneous renal biopsy. In the two cases reported here it is clear the arteriovenous fistula was produced during renal biopsy, as in both a loud continuous murmur, not previously present, became audible after biopsy, and in one case renal angiography was carried out before and after biopsy. The discovery of these two cases prompted the reappraisal of all the remaining cases in which renal biopsy had been carried out. These totalled 60 , but in none was a continuous murmur audible. This can probably be accepted as good evidence of the absence of arteriovenous fistula

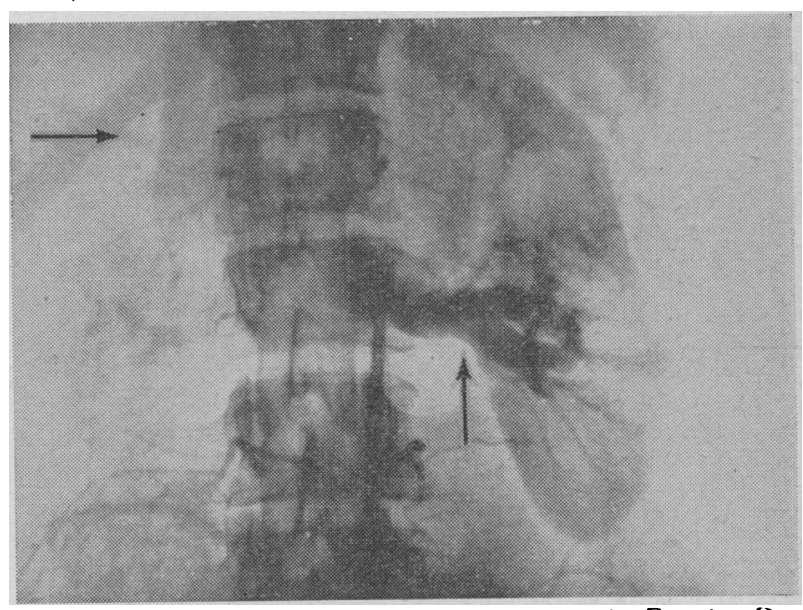

Fig. 2.-Case 1. Later tilm of same series as in Fig. 1. Dye visible in inferior vena cava (upper arrow).
cates a large renal vein.

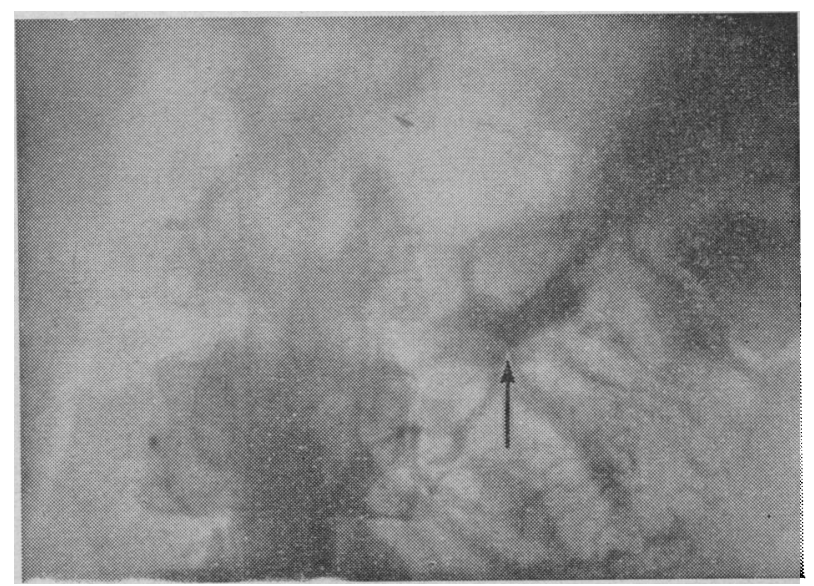

Fig. 4.-Case 2. Later film of same series as in Fig. 3, showing conspicuous densely filled venous channel. Arrow indicates large renal vein. 
of the kidney. Thus in a total of 62 cases there were two instances of arteriovenous fistula, giving an incidence of about $3 \%$.

The cause of arteriovenous fistula after biopsy is not clear. Boijsen and Kohler suggest that nephrosclerosis might be a factor by preventing normal contraction of the vessel wall at a puncture site. This is not likely in our Case 1, where biopsy showed normal renal vessels. It would appear that during biopsy the needle was directed too medially in these two cases, thereby increasing the chance of puncturing larger vessels, such as the arcuate. It is probable that the presence of hypertension increases the likelihood of fistula formation should the biopsy needle happen to puncture an adjacent artery and vein. In this series of 62 cases biopsy was performed during the investigation of hypertension in about $80 \%$. In Case 1 the B.P. was 150/90 on the day of biopsy, while in Case 2 it was 210/130. In the latter case the high B.P. may have been an important factor in the formation of the fistula, although it cannot have been so significant in Case 1 . It would seem prudent, however, to have the B.P. as near normal as possible at the time of the biopsy. This may not be easy to achieve, as many of the hypotensive agents are least effective when the patient is lying down, while any nervousness associated with the procedure will tend to elevate the B.P.

\section{Summary}

In a consecutive series of 62 cases of percutaneous renal biopsy renal arteriovenous fistula was produced in two. In $80 \%$ of the series biopsy was performed in the investigation of hypertension, and in the two reported cases the B.P. was considerably elevated in one and at the upper limit of normal in the other on the day of biopsy.

In view of these findings it would appear advisable to have the B.P. as near normal as possible at the time of renal biopsy, but the difficulties in achieving this are pointed out.

Renal arteriovenous fistula must be added to those complications of renal biopsy which are already recognized.

\section{REFERENCES}

Boijsen, E., and Kohler, R. (1962). Acta radiol. (Stockh.), 57,

Kerr, D. N. S. (1960). Lancet, 2, 1370

Twigg, H. L., Pradhan, R., and Perloff, J. K. (1962). Amer. J. Roentgenol., 88, 1148.

\section{Preliminary Communications}

\section{Lactation Due to Methyldopa}

Non-puerperal lactation, ordinarily an uncommon event (Dowling et al., 1961), has been reported in women treated with reserpine (Somlyo and Waye, 1960) and various of the phenothiazine tranquillizing agents (Hooper et al., 1961). Methyldopa has, in common with the above agents, the properties of sympatholytic activity and ready entrance into the central nervous system. It is of interest, therefore, that lactation has been observed in 5 out of 15 hypertensive women undergoing prolonged treatment with methyldopa. The pertinent clinical data appear in the Table.

\begin{tabular}{|c|c|c|c|c|c|}
\hline Patient & $\begin{array}{c}\text { Age } \\
\text { (Years) }\end{array}$ & $\begin{array}{l}\text { Daily Dose } \\
\text { Methyldopa } \\
\text { (g.) }\end{array}$ & $\begin{array}{c}\text { Duration } \\
\text { of } \\
\text { Treatment }\end{array}$ & Menopause & Menses \\
\hline $\begin{array}{l}1 \\
2 \\
3 \\
4 \\
5\end{array}$ & $\begin{array}{l}33 \\
40 \\
34 \\
45 \\
47\end{array}$ & $\begin{array}{l}2.75 \\
3.0 \\
3.75 \\
2.75 \\
2.0\end{array}$ & $\begin{array}{rl}13 & \text { months } \\
7 & \text { " } \\
14 & " \\
10 & " \\
12 & "\end{array}$ & 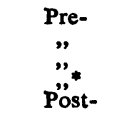 & $\begin{array}{l}\text { Normal } \\
\text { Amenorrhoea } \\
\text { = }\end{array}$ \\
\hline
\end{tabular}

As may be noted, lactation had occurred in both preand post-menopausal women. Breast secretions tended to be sparse and were observed spontaneously only by patients 1 and 2. Relationship of the medication to this phenomenon was verified when cessation of lactation occurred within three weeks in two subjects (Nos. 3 and 4) in whom the drug was discontinued. In patient 3 lactation ceased even though treatment was continued with another sympatholytic drug, guanethidine. Resumption of therapy with methyldopa in this patient resulted in recurrence of lactation. The amenorrhoea and breast enlargement and tenderness noted by this patient responded similarly to these changes in medication.

The mechanism underlying drug-induced lactation is open to conjecture. There is evidence in the studies of rabbits and rats of a hypothalamo-pituitary link of adrenergic nature which is necessary for normal pituitary-ovarian function (Markee et al., 1952). Surgical interruption of this link in humans has been reported to result in amenorrhoea and lactation (Ehni and Eckles, 1959). Chronic pharmacological interruption of this adrenergic pathway by sympatholytic agents could conceivably result in lactation or amenorrhoea, or both, as in patient 3 . Since guanethidine does not penetrate readily into the central nervous system the absence of lactation during treatment with this drug does not negate the aforementioned speculation.

Because of the frequency with which lactation occurred in women receiving large doses of methyldopa, a ready source of clinical material for endocrinological studies of this phenomenon is suggested.

William A. Pettinger, M.D.

DAVID HORWITZ, M.D.

Albert SJoerdsma, M.D., Ph.D.

Experimental Therapeutics Branch,

National Heart lnstitute,

Bethesda, Md., U.S.A.

REFERENCES

Dowling, J. T., Richards, J. B., Freinkel, N., and Ingbar, S. H. (1961). Arch. intern. Med., 107, 885.

Ehni, G., and Eckles, N. E. (1959). J. Neurosurg., 16, 628.

Hooper, J. H., Welch, V. C., and Shackelford, R. T. (1961). J. Amer. med. Ass., 178, 506.

Markee, J. E., Everett, J. W., and Sawyer, C. H. (1952). Recent

Progr. Hormone Res., 7, 139.

Somlyo, A. P., and Waye, J. D. (1960). J. Mt Sinai Hosp., 27, 5.

As a result of discussions with the Ministry of Health a Medical Instruments Group has been set up within S.I.M.A. (Scientific Instrument Manufacturers' Association of Great Britain) to provide a forum for the discussion of problems concerned with the application of instrumentation and equipment systems in medicine and in health and hygiene matters generally, including the hospital service. It is intended also to provide contact with those engaged in research in these fields, and with official bodies concerned with health matters. 